\title{
A Restriction Fragment of the C2 Gene Is a Unique Marker for C2 Deficiency and the Uncommon C2 Allele C2 *B (A Marker for Type 1 Diabetes)
}

\author{
Susan Simon, " Zuheir Awdeh, ${ }^{\star *}$ R. Duncan Campbell," Paul Ronco II,* Stuart J. Brink, ${ }^{* \| 1}$ \\ George S. Eisenbarth, ${ }^{* 1}$ Edmond J. Yunis, ${ }^{\star * \star *}$ and Chester A. Alper ${ }^{\star * \neq 1}$ \\ *The Center for Blood Research, ${ }^{\ddagger}$ Harvard Medical School, "The Children's Hospital, 'Joslin Diabetes Center, ${ }^{* *}$ Dana-Farber Cancer \\ Institute, Boston, Massachusetts 02115, and ${ }^{8}$ University of Oxford, Oxford OX1 3QU, United Kingdom
}

\begin{abstract}
There are three common $C 2$ protein alleles in caucasians, $C 2 * C, C 2 * B$, and $C 2 * Q 0$, with allele frequencies of 0.96 , 0.03 , and 0.01 , as well as Sst I RFLP variants of 2.75, 2.7, 2.65, 2.55 , and $2.4 \mathrm{~kb}$, with frequencies of $0.017,0.533,0.358,0.017$, and 0.075 . Thus, $C 2 * C$ is informatively split by the RFLP. Of 94 nonrandomly ascertained caucasian complotypes, 77 contained $C 2 * C$, four contained $C 2 * Q 0$, and 13 had $C 2 * B$. None of the $C 2 * C$-containing complotypes carried the $2.75 \mathrm{~kb}$ Sst I fragment and all of the complotypes with $C 2 * B$ or $C 2 * Q 0$ carried it. All of the $C 2 * Q 0$ alleles were associated with $C 4 A * 4, C 4 B * 2$ in the complotype $\mathrm{S} 042$ as previously reported. $C 2 * B$ was usually $(9 / 13)$ in the complotype SB42, occasionally (1/13 each) in SB45, SB41, SB(4,3)0, and SB31. Thus, the association of the $C 2$ 2.75-kb fragment was with $C 2 * B$ and $C 2 * Q 0$, not with $C 4 A * 4, C 4 B * 2$, or even $C 4 A * 4$ alone. The complotype SC42 was associated with the $2.65-\mathrm{kb}$ Sst I fragment in four of five instances and in a single example with the $2.7-\mathrm{kb}$ fragment. $C 2 * B$ and $C 2 * Q 0$ possibly had a common evolutionary ancestor complotype which carried the 2.75-kb Sst I fragment, and $B F * S, C 4 A * 4$, and $C 4 B * 2 . C 2 * B$ (particularly as the haplotype HLA-Bw62, SB42, DR4) is associated with type 1 diabetes but $C 2 * Q 0$ is protective. (J. Clin. Invest. 1991. 88:2142-2145.) Key words: human complement C2 $\cdot$ C2 gene $\cdot \mathrm{C2}$ allele $\cdot \mathrm{C2}$ deficiency restriction fragment length polymorphism
\end{abstract}

\section{Introduction}

There is a single gene for the human complement protein $\mathrm{C} 2,{ }^{1}$ situated telomeric to the genes for factor $\mathrm{B}(\mathrm{BF})$ and $\mathrm{C} 4(C 4 A$ and $C 4 B)$ and centromeric to HLA-B $(1,2)$ in the mid-portion

Address correspondence and reprint requests to Chester A. Alper, M.D., The Center for Blood Research, 800 Huntington Ave., Boston, MA 02115. 1991

Received for publication 01 July 1991 and in revised form 28 August

1. Abbreviations used in this paper: $\mathrm{BF}$, factor $\mathrm{B}$ of the alternative complement pathway; $\mathrm{C} 2$, the second component of complement; $\mathrm{C} 4$, the fourth component of complement; MHC, major histocompatibility complex; RFLP, restriction fragment length polymorphism.

J. Clin. Invest.

(c) The American Society for Clinical Investigation, Inc.

$0021-9738 / 91 / 12 / 2142 / 04 \$ 2.00$

Volume 88, December 1991, 2142-2145 of the short arm of the sixth human chromosome. C2 protein shows relatively little polymorphism in caucasian populations, with $\sim 96 \%$ of all chromosomes carrying the common allele $C 2 * C$ and around $3 \%$ carrying the gene for a more basic variant $C 2 * B(3-5)$. Around $1 \%$ of chromosomes have a null gene, $C 2 * Q 0$, which, in the homozygous state, is associated with a total absence of $\mathrm{C} 2$ protein in serum and with an increased risk for systemic lupus erythematosus (6). The $C 2 * Q 0$ allele has a grossly normal-sized gene in genomic DNA (7). Both $C 2 * B$ and $C 2 * Q 0$ are in very strong linkage disequilibrium with the specific alleles $B F * S, C 4 A * 4$, and $C 4 B * 2$, forming the complotypes (four allele sets behaving in populations and families as single genetic units) SB42 and S042 $(8,9)$. Less commonly, $C 2 * B$ was found on SB41, SB45, or SB43.

A multiallelic polymorphism in C2 genomic DNA is detected after digestion with Sst I (or several other enzymes) and Southern blotting with a 300-bp 5' C2 genomic probe (10-12). The variants represent differences in the size of an intron near the $5^{\prime}$ end of the $\mathrm{C} 2$ gene and include Sst I fragments of 2.4, $2.55,2.65,2.7$, and $2.75 \mathrm{~kb}$. They are of particular interest because they allow the subdivision of haplotypes with $C 2 * C$.

This report concerns the striking linkage disequilibrium of the $2.75-\mathrm{kb}$ Sst I variant in $\mathrm{C} 2$ genomic DNA with $C 2 * B$ and $C 2 * Q 0$ in the complotypes S042, SB42, SB45, SB41, SB(4,3)0, and SB31. SB42, SB45, SB41 and S042 carry most instances of $C 2 * B$ and $C 2 * Q 0$ in caucasian populations.

\section{Methods}

Subjects. Lymphoblastoid lines were established by Epstein-Barr virus transformation of peripheral blood B lymphocytes from members of 24 families in which at least one member had type 1 diabetes mellitus. In addition, lymphoblastoid lines were established from peripheral blood B lymphocytes of MHC homozygous individuals either by us or by the 10th International Histocompatibility Workshop (13). For the present study, a total of 94 independent normal and diabetic haplotypes were analyzed for the Sst I polymorphism in the 5' portion of the $\mathrm{C} 2$ gene. Of these, 54 diabetic and 37 normal haplotypes were randomly ascertained and were used for frequency comparisons. The compilation and analysis of normal and diabetic haplotypes were as previously described (14).

Complotype and HLA determinations. Plasma from whole blood collected into EDTA was used to test for genetic polymorphisms in C4 $(C 4 A$ and $C 4 B), \mathrm{BF}$, and $\mathrm{C} 2$ proteins. Complotypes were assigned from similar studies in immediate relatives. For $C 4$ typing (15), the plasma was treated with neuraminidase and, in some instances, carboxypeptidase (16) and then subjected to agarose gel electrophoresis and immunofixation with goat anti-human C4 (Atlantic Antibodies, Stillwater, $\mathrm{MN}$ ). $\mathrm{C} 2$ types were determined by isoelectric focusing in thin layer polyacrylamide gel and a $\mathrm{C} 2$-sensitive agarose gel overlay incorporat- 
ing antibody-sensitized sheep erythrocytes (3). Of the four haplotypes with $C 2 * Q 0$, two were in a homozygote and all were with HLA-B18 and DR2. For the two heterozygotes, half-normal C2 levels in serum were associated with the haplotype in family studies. BF typing (17) was by agarose gel electrophoresis and immunofixation with anti-human BF (Atlantic Antibodies). The nomenclature for $\mathrm{C} 4$ is that described previously $(15,18)$.

Individual alleles are italicized and designated by locus name in capital letters, an asterisk, and a number or "Q0" if null (e.g., $C 4 A * 4$, $C 4 B * 2$, or $C 4 B * Q 0$ ). Phenotypes, variants or proteins are given with roman capital letters, a space, and the same number or symbol as the corresponding allele (C4A 4, C4B 2, or C4B Q0). Complotypes are designated by their BF, C2, C4A, and C4B alleles, in that arbitrary order (9). Null or $\mathrm{Q} 0$ alleles are simply 0 . Thus, SB42 indicates the complotype $B F * S, C 2 * B, C 4 A * 4, C 4 B * 2$, and $\mathrm{S} 042$ is $B F * S$, $C 2 * Q 0, C 4 A * 4, C 4 B * 2$.

HLA-A, B, and DR generic typing was performed by standard methods (19). Extended haplotypes were defined previously as HLA-B, complotype, DR allele sets exhibiting significant linkage disequilibrium (20).

Restriction fragment length polymorphism (RFLP). DNA was extracted from the B lymphoblastoid lines by the method of Gross-Bellard and colleagues (21). $5 \mu \mathrm{g}$ of DNA were digested to completion with Sst I restriction endonuclease, using conditions recommended by the manufacturer (Bethesda Research Laboratories, Gaithersburg, MD). Electrophoresis of Sst I-digested DNA was carried out for $96 \mathrm{~h}$ at $60 \mathrm{~V}$ at $4^{\circ} \mathrm{C}$ in $2.0 \%$ agarose gel in $1 \mathrm{X}$ TAE $(0.04 \mathrm{M}$ Tris acetate $/ 0.002 \mathrm{M}$ EDTA) with continuous buffer circulation, in a minor modification of the method described previously (11).

DNA cleavage fragments were transferred to Nytran (Schleicher \& Schuell, Keene, NH) or Sure-blot membranes (Oncor, Gaithersburg, MD) (22). The 300-bp C2 probe was derived from the genomic clone pG850 and was described previously (10). It was labeled with alpha $\left[{ }^{32} \mathrm{P}\right] \mathrm{dCTP}$ by the random primer method (23). Prehybridization and hybridization were carried out at $45^{\circ} \mathrm{C}$, the latter overnight. Membranes were washed twice at room temperature with $0.1 \times$ standard saline citrate (SSC), $0.1 \%$ SDS, and a third time with the same solution at $52^{\circ} \mathrm{C}$ for $20-60 \mathrm{~min}$. The membranes were then exposed to $\mathrm{x}$-ray film with an intensifying screen at $-70^{\circ} \mathrm{C}$ for $2-5 \mathrm{~d}$ for autoradiography.

\section{Results}

In the overall set of chromosomes, including both normal and diabetic haplotypes, there were 77 instances of complotypes with $C 2 * C, 13$ with $C 2 * B$, and four with $C 2 * Q 0$ (including two from a deliberately selected homozygote). The C2 Sst I restriction fragment length variant of $2.75 \mathrm{~kb}$ was found only on haplotypes with the complotypes SB42, SB45, SB41, $\mathrm{SB}(4,3) 0, \mathrm{SB} 31$, and S042. The distribution of C2 Sst I variants with respect to $C 2$ protein alleles is seen in Table $I$. Of five examples of SC42, four were found on haplotypes that carried the 2.65-kb Sst I variant and one SC42 was with the $2.7-\mathrm{kb}$ fragment. All other complotypes carried only the previously described $C 2$ variants of $2.4,2.65$, or $2.7 \mathrm{~kb}$. The $\mathrm{C} 2$ variant of $2.55 \mathrm{~kb}$ was not encountered in this study.

In all instances, the $2.75 \mathrm{~kb}$ Sst I variant was inherited in the families in which it occurred in Mendelian fashion and in every case cosegregated with the $C 2 * B$ or $C 2 * Q 0$ variant-containing complotype. This is illustrated in Fig. 1 .

From the known frequencies of $C 2 * B(0.0282)$ and $C 2 * Q 0$ $(\sim 0.01)$ in a large population of normal caucasian chromosomes $(n=2,180)$, it can be estimated that the frequency of the 2.75 -kb Sst I C2 allele is 0.04 , assuming that it occurs only but invariably in association with these alleles. This is in the same
Table I. Sst I C2 DNA Variants in Relation to C2 Alleles

\begin{tabular}{lccc}
\hline & \multicolumn{3}{c}{ No. of examples } \\
\cline { 2 - 4 } C2 Sst I & $C 2 * C$ & $C 2 * B$ & $C 2 * Q 0$ \\
\hline 2.75 & 0 & 13 & 4 \\
2.7 & 35 & 0 & 0 \\
2.65 & 36 & 0 & 0 \\
2.4 & 6 & 0 & 0 \\
\hline
\end{tabular}

range as the frequency of 0.017 estimated directly on a relatively small number of normal caucasian haplotypes.

Of 59 randomly ascertained type 1 diabetes haplotypes, the 2.75-kb Sst I C2 fragment was found on 5, whereas it was found on two of 37 family control haplotypes. The relative risk for positivity for the $2.75-\mathrm{kb}$ Sst I C2 allele among patients with diabetes compared with family controls was 1.8 . The associations in the two populations of haplotypes were different. All instances on patient haplotypes were with $C 2 * B$, whereas in family normal control haplotypes, two independent instances were with $C 2 * Q 0$ and one was with $C 2 * B$.

To assess whether $C 2 * B$ is a significant marker for type 1 diabetes, its frequency among 365 independent Caucasian patient haplotypes was compared with that among 2180 normal Caucasian control haplotypes. $C 2 * B$ had a gene frequency of 0.0712 in diabetic haplotypes and 0.0271 in normal haplotypes

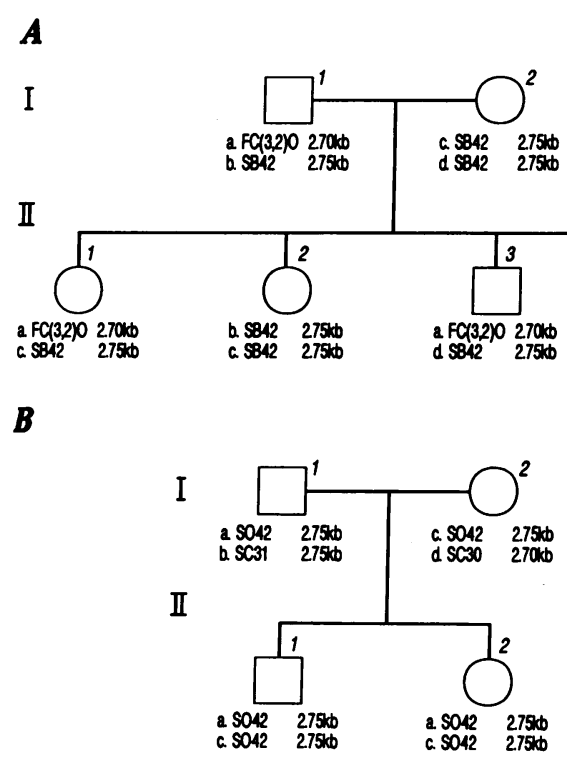

Figure 1. $(A)$ Family $\mathrm{C}$ with $C 2 * B$ in the complotype SB42. The mother of this family is homozygous for SB42 $(B F * S, C 2 * B, C 4 A * 4$, $C 4 B * 2)$ and the $2.75-\mathrm{kb}$ Sst I $C 2$ fragment. The father is heterozygous for these genetic markers. Two children, II-2 and II-4, are homozygotes who have coinherited SB42 and the C2 Sst I 2.75-kb fragment from both parents. The other two children, II- 1 and II-3, are heterozygotes, having inherited the a haplotype $(\mathrm{FC}(3,2) 0,2.7 \mathrm{~kb})$ from their father as well as the $c$ or $\mathrm{d}$ SB42, 2.75-kb haplotype (distinguished by other MHC genes, not shown) from their mother. ( $B)$ Family $\mathrm{H}$ with $C 2$ deficiency. The $C 2$ deficiency complotype $\mathrm{S} 042(B F * S, C 2 * Q 0$, $C 4 A * 4, C 4 B * 2$ ) segregates with the $2.75-\mathrm{kb} \mathrm{C} 2$ Sst I fragment from the father and mother. Both children are homozygous for $\mathrm{C} 2$ deficiency and the 2.75-kb Sst I C2 fragment. 
Table II. Possible Extended Haplotypes with C2*B on Independent Type 1 Diabetes and Normal Haplotypes

\begin{tabular}{lccccc}
\hline \multicolumn{1}{c}{ Haplotype } & \multicolumn{2}{c}{$\begin{array}{c}\text { Normal } \\
n=2180\end{array}$} & \multicolumn{2}{c}{$\begin{array}{c}\text { Diabetes } \\
n=365\end{array}$} & $\begin{array}{c}\text { Haplotype } \\
\text { ratio }\end{array}$ \\
\hline & $n$ & fraction & $n$ & fraction & $D / N$ \\
HLA-Bw62, SB42, DR4 & 9 & 0.0041 & 9 & 0.0247 & 6 \\
HLA-Bw55, SB45, DRw6 & 6 & 0.0027 & 1 & 0.0027 & 1 \\
HLA-Bw60, SB42, DR4 & 3 & 0.0014 & 2 & 0.0055 & 4 \\
HLA-B7, SB42, DR4 & 3 & 0.0014 & 2 & 0.0055 & 4 \\
HLA-B37, SB42, DR4 & 2 & 0.0009 & 0 & - & \\
HLA-B35, SB42, DR4 & 2 & 0.0009 & 0 & - &
\end{tabular}

There were 59 normal and 26 diabetes haplotypes with $C 2 * B$. Fraction refers to the number of such haplotypes shown divided by the total normal or diabetes haplotypes. $D / N$ refers to the ratio of frequencies among diabetes and normal haplotypes as specified.

$(P<0.0001$, relative risk for positivity for $C 2 * B=2.8)$. On the other hand, $C 2 * Q 0$, almost always on the extended haplotype [HLA-B18, S042, DR2] or its fragments, was found on $~ 1 \%$ of normal haplotypes but on no diabetic haplotype.

The MHC haplotypes on which $C 2 * B$ occurred more than once on either independent patient or independent normal haplotypes are shown in Table II. These haplotypes represent possible extended or conserved haplotypes. In both populations, the haplotype HLA-Bw62, SB42, DR4 was the most common. This haplotype was significantly increased among diabetic haplotypes $(P<0.0004)$. The haplotype HLA-Bw55, SB45, DRw6, previously suspected of being an extended haplotype, was noted on six normal haplotypes but only one patient haplotype. Other $C 2 * B$-bearing haplotypes were not increased among diabetics.

\section{Discussion}

Because the 2.75-kb Sst I C2 restriction fragment is always associated with the SB42, SB45, SB41, SB31, SB(4,3)0, or S042 complotypes and reflects an unusual size intron common to these complotypes, it is likely that $C 2 * B$ and $C 2 * Q 0$ had a common ancestor. Perhaps surprisingly, because S042 and SB42 may have arisen from SC42, the association does not include SC42 in caucasians. Thus, the extensive polymorphism in the $C 2$ gene detected with Sst I (10-12) or a number of other restriction enzymes (24), already shown to be capable of dividing haplotypes carrying $C 2 * C$ and $B F * F$ from those with $C 2 * C$ and $B F * S(25)$, is also useful in distinguishing $C 2 * B$, and $C 2 * Q 0$ from $C 2 * C$.

This is particularly important for $C 2 * Q 0$, for several reasons. Heterozygotes for $\mathrm{C} 2$ deficiency can be difficult to detect by measuring $C 2$ serum levels alone (26). Homozygotes have increased susceptibility to systemic lupus erythematosus and the availability of an additional indicator of the $\mathrm{C} 2$ null allele is clearly useful.

Our data confirm that $C 2 * B$ is increased in frequency among type 1 diabetics (27) and we now note a marked decrease in frequency or absence of $C 2 * Q 0$, undoubtedly related to the fact that the extended haplotype which usually carries it also carries HLA-DR2. Because the 2.75-kb RFLP variant is associated with both $C 2 * B$ (a marker for susceptibility to dia- betes) and $C 2 * Q 0$ (a marker for resistance), it is not as good a marker for disease susceptibility or resistance as the protein variants in $\mathrm{C} 2$.

We have found a number of $C 2 * B$-bearing haplotypes, some of which may be extended or conserved, particularly HLA-Bw62, SB42, DR4, and HLA-Bw55, SB45, DRw6. HLABw62, SB42, DR4 is a probable conserved or extended haplotype with a markedly increased frequency in diabetics. It clearly contributes to the associations of both $C 2 * B$ and DR4 with diabetes. These findings are consistent with previous observations of linkage disequilibrium between $C 2 * B$ and HLAB15(w62) $(5,28,29)$. The haplotype HLA-Bw55, SB45, DRw6 has been noted earlier to carry susceptibility for pemphigus vulgaris (30) and is probably a carrier of a defective CYP21 gene causing congenital adrenal hyperplasia (31).

\section{Acknowledgments}

We thank Deborah Marcus-Bagley for data handling, Dolores Fici and Maureen Oliver for the establishment of B lymphoblastoid cell lines, and Barbara Moore for complement typing. We thank Dr. Kenneth Gabbay for providing some of the cells or cell lines.

This work was supported by National Institutes of Health grants AI 14157 and DK 26844.

\section{References}

1. Carroll, M. C., R. D. Campbell, D. R. Bentley, and R. R. Porter. 1984. A molecular map of the human major histocompatibility complex class III region linking complement genes C4, C2 and factor B. Nature (Lond.). 307:237-241.

2. Dunham, I., C. A. Sargent, J. Trowsdale, and R. D. Campbell. 1987. Molecular mapping of the human major histocompatibility complex by pulsed-field gel electrophoresis. Proc. Natl. Acad. Sci. USA. 84:7237-7241.

3. Alper, C. A. 1976. Inherited structural polymorphism in human C2: evidence for genetic linkage between $C 2$ and Bf. J. Exp. Med. 144:1111-1115.

4. Hobart, M. J., and P. J. Lachmann. 1976. Allotypes of complement components in man. Transplant. Rev. 32:26-42.

5. Meo, T., J. Atkinson, M. Bernoco, D. Bernoco, and R. Ceppellini. 1976. Mapping of the HLA locus controlling $\mathrm{C} 2$ structural variants and linkage disequilibrium between alleles $\mathrm{C}^{2}$ and Bw15. Eur. J. Immunol. 7:916-919.

6. Agnello, V., M. M. E. de Bracco, and H. G. Kunkel. 1972. Hereditary C2 deficiency with some manifestations of systemic lupus erythematosus. J. Immunol. 108:837-840.

7. Cole, F. S., A. S. Whitehead, H. S. Auerbach, T. Lint, H. J. Zeitz, P. Kilbridge, and H. R. Colten. 1985. The molecular basis for genetic deficiency of the second component of human complement. N. Engl. J. Med. 313:11-16.

8. Awdeh, Z. L., D. D. Raum, D. Glass, V. Agnello, P. H. Schur, R. B. Johnston, Jr., E. W. Gelfand, M. Ballow, E. Yunis, and C. A. Alper. 1981. Complement-human histocompatibility antigen haplotypes in $\mathrm{C} 2$ deficiency. J. Clin. Invest. 67:581-583.

9. Alper, C. A., D. Raum, S. Karp, Z. L. Awdeh, and E. J. Yunis. 1983. Serum complement 'supergenes' of the major histocompatibility complex in man (complotypes). Vox Sang. 45:62-67.

10. Bentley, D. R., R. D. Campbell, and S. J. Cross. 1985. DNA polymorphism of the $C 2$ locus. Immunogenetics. 22:377-390.

11. Ratanachaiyavong, S., R. D. Campbell, and A. M. McGregor. 1989. Enhanced resolution of the SstI polymorphic variants of the $\mathrm{C} 2$ locus: description of a new size class. Hum. Immunol. 26:310-320.

12. Zhu, Z. B., and J. E. Volanakis. 1990. Allelic associations of multiple RFLPs of the gene encoding the complement protein C2. Am. J. Hum. Genet. 46:956-962.

13. Yang, S. Y., E. Milford, U. Hämmerling, and B. Dupont. 1989. Description of the reference panel of B-lymphoblastoid cell lines for factors of the HLA system: the B-cell line panel designed for the Tenth International Histocompatibility Workshop. In Immunobiology of HLA. Vol. I. B. Dupont, editor. SpringerVerlag, New York. 11-19.

14. Raum, D., Z. Awdeh, E. J. Yunis, C. A. Alper, and K. H. Gabbay. 1984. Extended major histocompatibility complex haplotypes in type 1 diabetes mellitus. J. Clin. Invest. 74:449-454.

15. Awdeh, Z. L., and C. A. Alper. 1980. Inherited structural polymorphism of the fourth component of human complement. Proc. Natl. Acad. Sci. USA. 77:3576-3580. 
16. Sim, E., and S. J. Cross. 1986. Phenotyping of human complement component C4, a class-III HLA antigen. Biochem. J. 239:763-767.

17. Alper, C. A., T. Boenisch, and L. Watson. 1972. Genetic polymorphism in human glycine-rich beta-glycoprotein. J. Exp. Med. 135:68-80.

18. Mauff, G., C. A. Alper, Z. Awdeh, J. R. Batchelor, J. Bertrams, G. BruunPetersen, R. L. Dawkins, P. Démant, J. Edwards, H. Grosse-Wilde, G. Hauptmann, P. Klouda, L. Lamm, E. Mollenhauer, C. Nerl, B. Olaisen, G. O'Neill, C. Rittner, M. H. Roos, V. Skanes, P. Teisberg, and L. Wells. 1983. Statement on the nomenclature of human C4 allotypes. Immunobiology. 164:184-191.

19. Zachary, A. A., and G. A. Teresi, editors. 1990. ASHI Laboratory Manual. 2nd ed. American Society for Histocompatibility and Immunogenetics, New York. 195-201.

20. Awdeh, Z. L., D. Raum, E. J. Yunis, and C. A. Alper. 1983. Extended HLA/complement allele haplotypes: evidence for $\mathrm{T} / \mathrm{t}$-like complex in man. Proc. Natl. Acad. Sci. USA. 80:259-263.

21. Gross-Bellard, M., P. Oudet, and P. Chambon. 1973. Isolation of high molecular weight DNA from mammalian cells. Eur. J. Biochem. 36:32-38.

22. Southern, E. M. 1975. Detection of specific sequences among DNA fragments separated by gel electrophoresis. J. Mol. Biol. 98:503-517.

23. Feinberg, A. P., and B. Vogelstein. 1984. Addendum to a technique for radiolabeling DNA restriction endonuclease fragments to high specific activity Anal. Biochem. 137:266-267.

24. Woods, D. E., M. D. Edge, and H. R. Colten. 1984. Isolation of a complementary DNA clone for the human complement protein $\mathrm{C} 2$ and its use in the identification of a restriction fragment length polymorphism. J. Clin. Invest. 74:634-638.

25. Bentley, D. R., and R. D. Campbell. 1986. C2 and factor B: structure and genetics. Biochem. Soc. Symp. 51:7-18.

26. Klemperer, M. R., H. C. Woodworth, F. S. Rosen, and K. F. Austen. 1966. Hereditary deficiency of the second component of complement (C2) in man. J. Clin. Invest. 45:880-890.

27. Rittner, C., and J. Bertrams. 1981. On the significance of C2, C4, and factor B polymorphisms in disease. Hum. Genet. 56:235-247.

28. Olaisen, B., P. Teisberg, T. Gedde-Dahl, Jr., and E. Thorsby. 1978. Genetic polymorphism of the second component of human complement (C2). Hum. Genet. 42:301-305.

29. Raum, D., D. Glass, C. B. Carpenter, P. H. Schur, and C. A. Alper. 1979. Mapping of the structural gene for the second component of complement with respect to the human major histocompatibility complex. Am. J. Hum. Genet. $31: 35-41$.

30. Ahmed, A. R., E. J. Yunis, K. Khatri, R. Wagner, G. Notani, Z. Awdeh, and C. A. Alper. 1990. Major histocompatibility complex haplotype studies in Ashkenazi Jewish patients with pemphigus vulgaris. Proc. Natl. Acad. Sci. USA. 87:7658-7662.

31. McCluskey, J., P. H. Kay, M. Stuckey, F. T. Christiansen, R. L. Dawkins, and G. Wilson. 1983. MHC "supratype" predicting heterozygous 21-hydroxylase deficiency. Lancet. i:764-765. 